\title{
T Early introduction and cumulative consumption of sugar-sweetened beverages during the pre-school period and risk of obesity at 8-14 years of age
}

\author{
A. Cantoral' ${ }^{1}$ M. M. Téllez-Rojo ${ }^{1}$, A. S. Ettinger ${ }^{2,3}$, H. Hu ${ }^{4}$ M. Hernández-Ávila ${ }^{1}$ and \\ K. Peterson ${ }^{3,5}$
}

${ }^{1}$ National Institute of Public Health, Cuernava, Morelos, Mexico; ${ }^{2}$ Department of Chronic Disease Epidemiology, Yale School of Public Health, New Haven, CT, USA; ${ }^{3}$ Department of Nutritional Sciences, University of Michigan School of Public Health, Ann Arbor, MI, USA; ${ }^{4}$ Dalla Lana School of Public Health, University of Toronto, Toronto, ON, Canada; ${ }^{5}$ Department of Nutrition and Department of Social and Behaviorial Sciences, Harvard School of Public Health, Boston, MA, USA

Address for correspondence: Dr A Cantoral, National Institute of Public Health, Av. Universidad 655, Santa María Ahuacatitlán, Cuernavaca 62100 Morelos, México. E-mail: alejandra.cantoral@insp.mx

Received 31 October 2014; accepted 24 February 2015

\section{Summary}

Background: Consumption of sugar-sweetened beverages (SSB) has been associated with risk of obesity, but little evidence exists to evaluate if age of introduction and cumulative SSB consumption increases risk in children.

Objectives: The objective of the study was to estimate the relationship between age of introduction and cumulative SSB consumption with risk of obesity in 227 Mexican children.

Methods: SSB intake was measured every 6 months; age of introduction and cumulative consumption during the pre-school period were calculated. Height, weight, waist circumference, SSB intake and other relevant variables were measured at age 8-14 years and obesity defined using standard criteria.

Results: All participants were introduced to SSB before age 24 months and most (73\%) before 12 months. Early SSB introduction ( $\leq 12$ months) was not significantly associated with increased odds of obesity (odds ratio $[\mathrm{OR}]=2.00,95 \%$ confidence interval [Cl]: 0.87, 4.59). However, children in the highest tertile of cumulative SSB consumption, compared with the lowest, had almost three times the odds of general (OR $=2.99,95 \% \mathrm{Cl}: 1.27,7.00)$ and abdominal $(\mathrm{OR}=2.70,95 \% \mathrm{Cl}: 1.03$, 7.03) obesity at age $8-14$ years.

Conclusions: High SSB consumption increased the likelihood of obesity in 8-14-year-old children. Our results suggest that SSB intake should be delayed and excessive SSB consumption in pre-school period should be avoided.

Keywords: Children, obesity, pre-school, sugar-sweetened beverages.

\section{Introduction}

During the past two decades, overweight and obesity have been increasing among children and adolescents worldwide. According to the World Health Organization, over 42 million children under the age of five were overweight or obese in 2013. At the same time, consumption of sugar-sweetened beverages (SSB), defined as liquids that are sweetened with various forms of sugars (e.g., soda, fruit drinks, sport and energy drinks) (1), has been increasing $(2,3)$. SSB represent the largest source of added sugars and significantly contributes to calories in children's diets (4). In younger children, the Feeding Infants and Toddlers Study reported that $10.7 \%$ of infants aged $9.0-11.9$ months and $14.3 \%$ of children aged 12.0-14.9 months consumed SSB on a given day (5).
SSB provide little nutritional benefit, and previous studies have reported that high intakes during childhood are associated with negative health outcomes such as dental caries (6), weight gain (7) and enlarged waist circumference. Increased risk of weight gain has been attributed to the body's low satiety response to liquid calories and the failure to compensate for excess caloric intakes $(8,9)$.

Mexico is among the countries with the highest consumption of caloric beverages contributing $20-23 \%$ of the total energy intake in the population $(2,10)$. From 19992006 , a $226 \%$ increase in consumption of caloric beverages was documented among Mexican children and adolescents $(2,10)$. The 2012 Mexican National Health and Nutrition Survey reported the prevalence of overweight and obesity, respectively, of $19.8 \%$ and $14.6 \%$ in children (5-11 years of age) and of $21.6 \%$ and $13.3 \%$ in adolescents (12-19 years old) (11). 
Increased attention has focused on reducing SSB intake in an effort to reduce overweight/obesity, particularly in children. The American Academy of Pediatrics recommends that sweetened beverages, such as naturally sweet beverages and fruit juice, should be limited to 4-6 oz d $\mathrm{d}^{-1}$ for children 1-6 years old and to $8-12 \mathrm{oz} \mathrm{d}^{-1}$ for children 7-18 years old (12). In Mexico, government agencies suggest several actions: the Mexican National Beverage Guidelines recommended an intake of only $4 \mathrm{oz} \mathrm{d}^{-1}$ of natural juices in children with no intake of other SSB (13); the National Agreement for Healthy Nutrition included the reduction of fat and sugar beverages as primary objectives (14), and the School Guideline for Healthy Foods recommended the consumption of natural juices or water with fresh fruit (commonly consumed in Mexico) only one to two times per week in a maximum amount of $4 \mathrm{oz}(120 \mathrm{~mL})$ per serving during school lunches (15).

Previous studies report that children who consumed SSB during infancy increased the likelihood of consuming SSB later in childhood (16) and had higher odds of childhood obesity than non-SSB consumers (17). The aim of this study was to estimate the relationships between: (i) age of introduction to SSB and (ii) cumulative consumption of SSB during the pre-school period with risk of obesity at 8-14 years of age in a prospective birth cohort study of Mexican children with repeated measures of diet in early life.

\section{Methods}

\section{Study population}

This study included children born from two birth cohort studies from the Early Life Exposure in Mexico to Environmental Toxicants (ELEMENT) project, which has been described previously $(18,19)$. Pregnant women were enrolled between 1997 and 2002 during the first trimester of pregnancy and 1079 children born to these women were assessed for growth and development at 6-month intervals from birth to 5 years of age. Beginning at the 12-month visit, diet was assessed to identify when the child was introduced to SSB and the amounts consumed. Other relevant measurements were recorded including: maternal and infant anthropometry and information about breastfeeding practices.

Between 2008 and 2009, 622 of the original cohort children (58\%) were enrolled in a follow-up study, and in 2010, a convenience sample of 250 children were selected when they were between 8 and 14 years old as part of an National Institute of Environmental Health Sciences (NIEHS)/Environmental Protection Agency (EPA) P20 Formative Children's Environmental Health (CEH) Centre. The purpose of the Formative CEH Centres was to foster and stimulate new research ideas that were in the early phase of scientific inquiry, so the number of participants represents only a subset of the children born to the original birth cohorts. Mothers and their children were apprised of the follow-up study objectives and procedures and signed an informed consent or child assent prior to participation. From those, 227 (91\%) had complete information for all of the relevant socio-demographic, dietetic, anthropometric and physical activity variables for this study $(n=23$ participants were missing information on mother's body mass index [BMI] or breastfeeding practices). This study was evaluated and approved by the Research, Ethics and Biosafety Committees of the National Institute of Public Health of Mexico, the Institutional Review Board of the University of Michigan and the Institutional Review Board from the Harvard School of Public Health.

\section{Dietary assessment}

Diet was assessed using a semi-quantitative food frequency questionnaire (FFQ), which was validated by Hernández-Ávila et al. (20) using the Willett methodology. Trained personnel administered the FFQ to the mother at each visit beginning when the child was 12 months old. The FFQ was used to estimate dietary intakes over the previous 3 months.

The FFQ included 116 foods grouped into 10 categories (dairy products, fruits, vegetables, legumes, cereals, sweets, fats, snacks, eggs and meats) and beverages (natural juices, milk, sodas, commercial fruit drinks and flavoured water with sugar). Ten reported frequency values (ranging from never to six or more times a day) were used to calculate average daily frequencies: $0=$ never, $0.016=$ less than once a month, $0.08=$ two to three times a month, $0.14=$ once a week, $0.43=$ two to four times a week, $0.8=$ five to six times a week, $1=$ once a day, $2.5=$ two to three times a day, $4.5=$ four to five times a day and $6=$ six or more times a day. These frequencies were then multiplied by the standard serving size of each reported item to obtain average daily intakes (beverages, $\left.\mathrm{mL} \mathrm{d}^{-1}\right)$.

We considered SSB as the sum of daily intake of sodas, commercial fruit drinks and flavoured water with sugar (not including natural fruit or vegetable juices). Average daily intake of SSB $\left(\mathrm{mL} \mathrm{d}^{-1}\right)$ was multiplied by the number of days since the last interview, and then summed over all visits to calculate the cumulative consumption of SSB $(\mathrm{mL})$ during the pre-school period (age 1-5 years). Cumulative consumption of SSB was then categorized into tertiles. Using information provided in the $F F Q$, we calculated the age in months when infants started consumption of SSB and dichotomized this information as initiating SSB consumption $\leq 12$ months or $>12$ months of age.

At the revisit stage (8-14 years of age), we administered the FFQ used in the 2006 Mexican National Health and Nutrition Survey (ENSANUT 2006) directly to the children who were assisted by their mothers, when necessary, particularly at the younger ages. This instrument used a 1-week recall period and queried about the consumption of natural juices, commercial fruit drinks, flavoured water with sugar, tap water, sodas, diet sodas, whole fat milk, coffee and tea. Average energy intake (kcal) derived from reported food and beverage consumption was also calculated and, from this information, we obtained the SSB and non-SSB energy intakes. 


\section{Anthropometric measurements}

Weight, height and waist circumference were obtained using standardized procedures by trained personnel at the revisit stage (8-14 years of age). Weight was measured with a Bame scale (model 420, Puebla, Mexico) rounded to the nearest $0.1 \mathrm{~kg}$; height was recorded with a stadiometer (Perspective Enterprises, Portage, WI, USA) to the nearest $0.1 \mathrm{~cm}$; and waist circumference was obtained using a measuring tape (Quick Medical, Issaquah, WA, USA) to the nearest $0.1 \mathrm{~cm}$.

Weight and height were used to calculate BMl $\left(\mathrm{kg} \mathrm{m}^{-2}\right)$ and participants were classified as 'obese' according to the World Health Organization (WHO) criteria (21) (>2 standard deviation [SD] of the $z$-score for BMI), using WHO Anthro (version 3.2.2, January 2011, World Health Organization, Geneva, Switzerland) software. Waist circumference $\geq 90$ th percentile for age and sex was used to define abdominal obesity (22). We obtained concurrent information of the following variables: hours watching TV per week (as a proxy for inactivity) and hours of physical activity per week using a validated questionnaire (23).

\section{Other covariates}

We identified the presence of maternal obesity $\left(\mathrm{BMl} \geq 30 \mathrm{~kg} \mathrm{~m}^{-2}\right.$ ) using the anthropometric measurements at 12 months post-partum. We also created a dummy variable indicating any breastfeeding up to 12 months of age. We estimated socioeconomic status (SES) using the standard criteria of the Asociación Mexicana de Agencias de Investigación which classifies households into six levels according to family income in Mexican pesos per month.

\section{Statistical analysis}

Descriptive data are presented as means ( \pm SDs) or proportions (depending on the measurement scale of the corresponding variable) and stratified by the age of introduction SSB $\left(\chi^{2}\right.$ test and $t$-test, according to the scale of measure). We tested the normality of the distribution of concurrent SSB consumption with a Shapiro-Wilk test and rejected the hypothesis that it was normally distributed $(P<0.01)$. We performed a test for trend to compare concurrent SSB intake between participants by tertiles of cumulative SSB consumption during the pre-school period. We examined the Spearmen correlations between concurrent intake and cumulative SSB consumption.

To assess the relationship between: (i) age of introduction to SSB ( $\leq 12$ months and $>12$ months) and (ii) cumulative consumption of SSB ( $\mathrm{mL}$, tertiles) during the preschool period (age 1-5 years) with the odds of obesity at 8-14 years of age, we performed logistic regression both unadjusted and adjusted by: child sex, any breastfeeding up to age 12 months (yes/no), maternal obesity (BMI $\geq 30 \mathrm{~kg} \mathrm{~m}^{-2}$ at 12 months post-partum), concurrent age (years), non-SSB-energy intake (kcal), physical activity $\left(\mathrm{h}_{\text {week }}{ }^{-1}\right.$ ) and TV watching (h week ${ }^{-1}$ ).
All statistical analyses were performed using STATA 11.0 (StataCorp LP, College Station, TX, USA).

\section{Results}

Characteristics of the study participants are presented in Table 1. Among the 227 participants, 46\% were men and the majority (47\%) was between 8 and 9 years old. Most participants (73\%) were introduced to SSB before 12 months of age and all participants had initiated SSB consumption by age 24 months.

Thirty-one percent of the children were at least partially breastfed through 12 months of age and there were no overweight or obese children. However, at 8 to 14 years, obesity prevalence increased to $22.4 \%$ with no statistical difference between sexes (boys 47\%, girls 53\%, $P=0.8$ ). There was a significant correlation between the BMI $z$-score at 12 months and the BMI z-score at 8-14 years $(r=0.20, P=0.005)$.

On average (mean $\pm \mathrm{SD})$, children spent $4 \mathrm{~h} \mathrm{~d}^{-1}(4.0 \pm$ 0.91) watching TV while less than $1 \mathrm{~h} \mathrm{~d}^{-1}(0.82 \pm 0.47)$ was spent on physical activity at age 8-14 years. Average total energy intake was 2,637 ( \pm 844$) \mathrm{kcal}$ with SSB contributing $6.7 \%$ of total calories. There were no statistically significant differences in the age of introduction SSB by socioeconomic status and 94\% of participants had SES corresponding to a monthly family income level less than $\$ 35000$ Mexican pesos (equivalent to approximately \$2333 US dollars).

Concurrent SSB consumption $\left(\mathrm{mL} \mathrm{d}^{-1}\right)$, at 8-14 years of age, was positively correlated with the cumulative SSB intake during pre-school period $(r=0.22, P<0.01)$ (Supplemental Figure S1). There were no significant differences in concurrent consumption (median $\mathrm{mL} \mathrm{d}^{-1}$ ) of water, milk, sweetened tea or coffee, or natural juices by cumulative SSB intake (in tertiles) during the pre-school period. However, there was a significant difference in concurrent SSB consumption by tertiles of cumulative SSB intake during preschool period (Table 2). The mean $( \pm$ SD) daily concurrent SSB intake was 333.5 ( \pm 293.3$)$ $\mathrm{mL}, 397( \pm 340.4) \mathrm{mL}$ and $534( \pm 387.5) \mathrm{mL}$, respectively, for the first, second and third tertiles ( $P$-trend <0.01). Children in the highest tertile of preschool SSB consumption had the highest concurrent intake of soda at 8-14 years of age $\left(253.8 \pm 301.1 \mathrm{~mL} \mathrm{~d}^{-1}\right.$, compared with those in the lowest tertile $121.5 \pm 151.6 \mathrm{~mL} \mathrm{~d}^{-1}$, $P$-trend $<0.01)$. No diet soda intake was reported in our sample.

Early SSB introduction ( $\leq 12$ months) was associated with increased odds of obesity (odds ratio [OR] $=2.00$, 95\% confidence interval $[\mathrm{Cl}]: 0.87,4.59)$ and abdominal obesity $(\mathrm{OR}=1.70,95 \% \mathrm{Cl}: 0.70,4.09)$ although these results were not statistically significant (Table 3 ). With increasing cumulative SSB intake during the pre-school period, there was a statistically significant trend for increasing general $(P=0.01)$ and abdominal $(P=0.03)$ obesity. Children in the highest tertile of cumulative SSB consumption, compared with the lowest tertile of cumulative SSB intake, had almost three times the odds of general 
Table 1. Characteristics of the participants $(N=227)$

\begin{tabular}{|c|c|c|c|c|}
\hline & \multirow{3}{*}{$\begin{array}{l}\text { All }(N=227) \\
\text { Mean }(\mathrm{SD}) \\
\text { or } N(\%)\end{array}$} & \multicolumn{2}{|c|}{ Age of introduction to SSB } & \multirow[t]{3}{*}{$P$-value } \\
\hline & & \multirow{2}{*}{$\begin{array}{c}\leq 12 \text { months } \\
(N=166) \\
\text { Mean }(\mathrm{SD}) \\
\text { or } N(\%)\end{array}$} & \multirow{2}{*}{$\begin{array}{l}>12 \text { months } \\
(N=61) \\
\text { Mean }(\mathrm{SD}) \\
\text { or } N(\%)\end{array}$} & \\
\hline & & & & \\
\hline \multicolumn{5}{|l|}{ Sex } \\
\hline Male & $104(46)$ & $75(45)$ & $29(47)$ & 0.75 \\
\hline Female & $123(54)$ & $91(74)$ & $32(26)$ & 0.75 \\
\hline \multicolumn{5}{|l|}{ Age (years) } \\
\hline $8-9$ & $106(47)$ & $85(51)$ & $21(34)$ & 0.02 \\
\hline $10-11$ & $71(31)$ & $40(24)$ & $31(51)$ & $<0.01$ \\
\hline $12-14$ & $50(22)$ & $41(25)$ & $9(15)$ & 0.10 \\
\hline \multicolumn{5}{|l|}{ SES level (pesos/month)* } \\
\hline E (\$0 to $\$ 2699)$ & $17(8)$ & $13(8)$ & $4(7)$ & 0.71 \\
\hline $\mathrm{D}(\$ 2700$ to $\$ 6799)$ & $43(20)$ & $30(19)$ & $13(22)$ & 0.63 \\
\hline $\mathrm{D}+(\$ 6800$ to $\$ 11599)$ & $111(51.3)$ & $80(51)$ & $31(52)$ & 0.83 \\
\hline C (\$11 600 to $\$ 34999)$ & $42(19.3)$ & $31(20)$ & $11(19)$ & 0.85 \\
\hline$C+(\$ 35000$ to $\$ 84999)$ & $3(1.4)$ & $3(2)$ & 0 & 0.28 \\
\hline $\mathrm{A} / \mathrm{B}(>\$ 85000)$ & 0 & - & - & - \\
\hline Obesity (>2 SD BMl z-score) & $51(22)$ & $42(25.3)$ & $9(14.7)$ & 0.09 \\
\hline Waist circumference $>90$ th percentile & $44(19.4)$ & $35(21.1)$ & $9(14.7)$ & 0.28 \\
\hline TV watching $\left(\mathrm{h}\right.$ week $\left.{ }^{-1}\right)$ & $24.0(6.4)$ & $23.8(6.4)$ & $24(6.1)$ & 0.87 \\
\hline Physical activity (h week ${ }^{-1}$ ) & $5.8(3.3)$ & $5.6(3.1)$ & $6.2(3.7)$ & 0.35 \\
\hline Total energy intake $\left(\mathrm{kcal} \mathrm{d}^{-1}\right)$ & 2637 (844) & $2661(820)$ & $2571(910)$ & 0.47 \\
\hline Non-SSB-energy intake $\left(\mathrm{kcal} \mathrm{d}^{-1}\right)$ & $2465(809)$ & $2487(784)$ & $2406(877)$ & 0.50 \\
\hline Percentage of total energy from SSB intake & $6.7(5.5)$ & $6.6(5.4)$ & $6.2(5.3)$ & 0.64 \\
\hline Tap water $\left(m L \mathrm{~d}^{-1}\right)$ & $522(452)$ & $553(476)$ & 437 (372) & 0.08 \\
\hline Whole milk $\left(m L d^{-1}\right)$ & $515(251)$ & $519(256)$ & $507(240)$ & 0.76 \\
\hline Natural juice $\left(m L d^{-1}\right)$ & $39(62)$ & $38(59)$ & $42(68)$ & 0.71 \\
\hline Tea or coffee with sugar added $\left(\mathrm{mL} \mathrm{d}^{-1}\right)$ & 77 (124) & $81(137)$ & $64(76)$ & 0.35 \\
\hline $\operatorname{SSB}\left(m L d^{-1}\right)$ & $421(352)$ & $426(348)$ & $403(364)$ & 0.66 \\
\hline Soda $\left(m L d^{-1}\right)$ & $177(233)$ & $173(222)$ & $186(264)$ & 0.70 \\
\hline Sweetened fruit drinks $\left(m L d^{-1}\right)$ & $244(275)$ & $253(283)$ & $217(255)$ & 0.38 \\
\hline Maternal obesity at 12 months post-partum & $47(21)$ & $34(20.5)$ & $13(21.3)$ & 0.89 \\
\hline Partial breastfeeding until 12 months of age & $70(31)$ & $51(30.7)$ & $19(31.1)$ & 0.95 \\
\hline \multicolumn{5}{|l|}{ Cumulative SSB intake during pre-school period } \\
\hline First tertile (1642-15 $242 \mathrm{~mL})$ & $78(34.4)$ & $53(32)$ & $25(41)$ & 0.20 \\
\hline Second tertile (15 410-22 $484 \mathrm{~mL}$ ) & $74(32.6)$ & $55(33)$ & $19(31)$ & 0.77 \\
\hline Third tertile (22 731-55 $913 \mathrm{~mL})$ & 75 (33) & $58(35)$ & $17(28)$ & 0.31 \\
\hline
\end{tabular}

*According to the Asociación Mexicana de Agencias de Investigación, levels for family income in Mexican pesos per month ( $N=11$ missing information on SES level). BMI, body mass index; SD, standard deviation; SES, socioeconomic status; SSB, sugar-sweetened beverages.

$(\mathrm{OR}=2.99, \quad 95 \% \quad \mathrm{Cl}: 1.27,7.00)$ and abdominal $(\mathrm{OR}=2.70,95 \% \mathrm{Cl}: 1.03,7.03)$ obesity at age $8-14$ years.

Maternal obesity at 12 months post-partum also significantly increased the odds of the child being generally $(\mathrm{OR}=2.81,95 \% \mathrm{Cl}: 1.32,5.95)$ and abdominally $(\mathrm{OR}=3.97,95 \% \mathrm{Cl}: 1.79,8.77)$ obese at 8-14 years of age. Breastfeeding until 12 months of age appeared to decrease the odds of obesity by about $40-50 \%$, but these results were not statistically significant.

\section{Discussion}

This study documented the early introduction of SSB in Mexican children's diets and indicated that the cumulative amount of SSB consumed in pre-school period (age 1-5 years) was associated with risk of both general and abdominal obesity in later childhood. This is consistent with previous findings that have linked SSB intake to obesity in children $(17,24)$. 
Table 2 Concurrent beverage consumption $\left(\mathrm{mL} \mathrm{d}^{-1}\right)$ by tertiles of cumulative SSB intake during the pre-school period $(N=227)$

\begin{tabular}{|c|c|c|c|c|c|c|c|}
\hline \multirow[b]{3}{*}{ Concurrent beverage consumption $\left(\mathrm{mL} \mathrm{d}^{-1}\right)$} & \multicolumn{6}{|c|}{ Cumulative SSB intake } & \multirow[t]{3}{*}{$P$-trend } \\
\hline & \multicolumn{2}{|c|}{$\begin{array}{l}\text { First tertile } \\
(N=78) \\
\end{array}$} & \multicolumn{2}{|c|}{$\begin{array}{l}\text { Second tertile } \\
(N=74)\end{array}$} & \multicolumn{2}{|c|}{$\begin{array}{l}\text { Third tertile } \\
(N=75)\end{array}$} & \\
\hline & Mean & SD & Mean & SD & Mean & SD & \\
\hline Tap water & 513.5 & 448.0 & 536.1 & 416.5 & 517.3 & 494.4 & 0.98 \\
\hline Whole milk & 480.7 & 250.5 & 511.7 & 205.8 & 555.7 & 287.3 & 0.09 \\
\hline Natural juice & 32.1 & 54.2 & 50.3 & 73.4 & 35.4 & 55.8 & 0.68 \\
\hline Tea or coffee with sugar added & 62.5 & 103.0 & 90.8 & 155.3 & 77.9 & 108.7 & 0.48 \\
\hline SSB (soda + sweetened fruit drinks) & 333.5 & 293.3 & 397.0 & 340.4 & 534.0 & 387.5 & $<0.01$ \\
\hline Soda & 121.5 & 151.6 & 157.3 & 205.9 & 253.8 & 301.1 & $<0.01$ \\
\hline Sweetened fruit drinks & 212.0 & 250.1 & 239.8 & 265.5 & 280.2 & 307.5 & 0.33 \\
\hline
\end{tabular}

BMI, body mass index; SD, standard deviation; SSB, sugar-sweetened beverages.

Table 3 OR $(95 \% \mathrm{Cl})$ for obesity and abdominal obesity at 8-14 years of age by age of introduction to SSB, cumulative intake of SSB (tertiles) during the pre-school period, and covariates $(N=227)$

\begin{tabular}{|c|c|c|c|c|c|c|c|c|}
\hline & \multicolumn{4}{|c|}{ Obesity (>2 SD BMI z-score) } & \multicolumn{4}{|c|}{ Abdominal obesity (WC >90th percentile) } \\
\hline & \multicolumn{2}{|c|}{ Unadjusted } & \multicolumn{2}{|c|}{ Adjusted } & \multicolumn{2}{|c|}{ Unadjusted } & \multicolumn{2}{|c|}{ Adjusted } \\
\hline & OR & $95 \% \mathrm{Cl}$ & OR & $95 \% \mathrm{Cl}$ & OR & $95 \% \mathrm{Cl}$ & OR & $95 \% \mathrm{Cl}$ \\
\hline \multicolumn{9}{|l|}{ Age of introduction to SSB (months) } \\
\hline$>12$ & Ref & - & Ref & - & Ref & - & Ref & - \\
\hline$\leq 12$ & 1.86 & $0.83,4.18$ & 2.00 & $0.87,4.59$ & 1.45 & $0.64,3.28$ & 1.70 & $0.70,4.09$ \\
\hline \multicolumn{9}{|l|}{ Cumulative SSB intake } \\
\hline First tertile (1642-15 $242 \mathrm{~mL})$ & Ref & - & Ref & - & Ref & - & Ref & - \\
\hline Second tertile (15 410-22 $484 \mathrm{~mL}$ ) & 0.84 & $0.34,2.02$ & 0.84 & $0.32,2.13$ & 1.15 & $0.47,2.80$ & 1.14 & $0.42,3.07$ \\
\hline Third tertile (22 731-55 $913 \mathrm{~mL}$ ) & 2.69 & $1.25,5.79$ & 2.99 & $1.27,7.00$ & 2.29 & $1.01,5.19$ & 2.70 & $1.03,7.03$ \\
\hline \multicolumn{9}{|l|}{ Covariates } \\
\hline Sex (female) & & & 0.84 & $0.42,1.67$ & & & 2.02 & $0.93,4.35$ \\
\hline Age (years) & & & 0.91 & $0.72,1.14$ & & & 0.83 & $0.63,1.06$ \\
\hline $\begin{array}{l}\text { Non-SSB energy intake } \\
\quad\left(\text { per } 100 \mathrm{kcal} \mathrm{d}^{-1}\right)\end{array}$ & & & 0.99 & $0.99,1.00$ & & & 0.99 & $0.99,1.00$ \\
\hline TV watching $\left(\mathrm{h}\right.$ week $^{-1}$ ) & & & 1.01 & $0.95,1.06$ & & & 1.04 & $0.97,1.10$ \\
\hline Physical activity $\left(\mathrm{h}\right.$ week $\left.^{-1}\right)$ & & & 0.96 & $0.85,1.08$ & & & 0.89 & $0.77,1.02$ \\
\hline $\begin{array}{l}\text { Breastfeeding up to } 12 \text { months } \\
\text { of age }\end{array}$ & & & 0.59 & $0.27,1.26$ & & & 0.44 & $0.18,1.04$ \\
\hline $\begin{array}{l}\text { Maternal obesity at } 12 \text { months } \\
\text { post-partum }\end{array}$ & & & 2.81 & $1.32,5.95$ & & & 3.97 & $1.79,8.77$ \\
\hline
\end{tabular}

BMI, body mass index; Cl, confidence interval; OR, odds ratio; SD, standard deviation; SSB, sugar-sweetened beverages; Ref, reference category; WC, waist circumference.

Early SSB introduction ( $\leq 12$ months) was associated with increased odds of obesity although this result was not statistically significant. This could be because almost all (73\%) of the children started consumption of SSB at or before 12 months, which implies a small sample size in the category of introduction after 12 months of age. However, we documented that these pre-school habits with respect to SSB intake persist later in childhood. Those participants with the highest concurrent SSB intakes, especially of soda, were children who were in the highest tertile of cumulative SSB consumption in the first years of life, which is also consistent with previous findings (16).

Our results indicate that maternal obesity at 12 months post-partum was also significantly associated with increased likelihood of childhood obesity. This could be due to shared environmental factors, such as similar household diets, or to other yet unknown early life factors that trigger abnormal metabolic responses. Breastfeeding until 12 months of age may protect children against obesity later in life which is plausible because it may delay the 
introduction of SSB and also diminishes the risks of abdominal adiposity (25). However, our results indicating about a 40-50\% reduction in risk were not statistically significant possibly because only about $30 \%$ of the sample received any breastfeeding through 12 months of age and we did not evaluate exclusive breastfeeding.

We found no association between non-SSB energy intake and obesity which could be due to underreporting of dietary intake by overweight or obese participants, which has been demonstrated previously (26). This could also be due to reverse causality, in so far as those children (particularly adolescents) who are overweight or obese may diminish their overall intakes in order to lose weight. Previous reports have shown that not adjusting for total energy in the association between SSB and body weight in children generated larger estimates (27). In our study, we adjusted for non-SSB-energy as a covariate; however, in models excluding this covariate, the results were very similar (data not shown).

One of the limitations is the measurement error associated with the dietary assessment, specifically for the FFQ, as respondents' recall plays a major role in their responses (28). However, the FFQ is the method most applied to measure SSB intake compared with other assessment methods. Also, evaluation of diet in early childhood is complex and potentially contributing to errors is the possibility that dietary habits change rapidly at young ages, parents share their feeding responsibility with other adult caregivers, and children do not necessarily consume all the food they are given (29). Finally, the way in which we constructed our exposure variable (total SSB consumption) assumed that the reported intake was constant during the included months.

Previous cohort studies have reported no association between sweet drink intake and changes in weight or adiposity (30), but in this prospective study, one of the main strengths was the ability to capture children's beverage intakes from the time of first introduction with the use of a series of repeated measures design over the four-year pre-school period. These results confirm previous findings and suggest that delaying the introduction of SSB intake and limiting cumulative SSB consumption in early childhood is an important strategy to help avoid overweight and obesity in later years. New policies of taxing sodas with corresponding nutrition education could be a positive intervention on the population level and should be evaluated in future studies.

\section{Conflicts of interest statement}

The authors declare no conflicts of interest. This study was supported by: the US NIEHS (P01-ES022844, R01ES021446, R01-ES005947), Consejo Nacional de Ciencia y Tecnologia (CONACYT) 41912-M, and the NIEHS/US EPA Formative Children's Center for Environmental Health and Disease Prevention Research (NIH P2O-ES018171/ EPA RD\#834800). It represents the views of the authors and does not imply endorsement by the $\mathrm{NIH}$ or EPA.

\section{Acknowledgements}

We acknowledge the American British Cowdray Medical Center for providing the research facilities to conduct the study, which made it possible. AC and MMTR designed and conducted the research and analysed the data; MHA and $\mathrm{HH}$ provided essential materials and interpretation of the results; AC, MMTR, ASE, KEP and MHA wrote the paper; AC, MMTR, ASE and KEP had primary responsibility for final content. All authors have read and approved the final paper.

\section{References}

1. US Department of Agriculture. Dietary Guidelines for Americans. 7th edn. Government Printing Office: Washington, DC, 2010.

2. Barquera S, Hernandez-Barrera L, Tolentino ML, et al. Energy intake from beverages is increasing among Mexican adolescents and adults. J Nutr 2008; 138: $2454-$ 2461.

3. Wang YC, Bleich SN, Gortmaker SL. Increasing caloric contribution from sugar-sweetened beverages and 100\% fruit juices among US children and adolescents, 19882004. Pediatrics 2008; 121: e1604-e1614.

4. Welsh JA, Sharma AJ, Grellinger L, Vos MB. Consumption of added sugars is decreasing in the United States. Am J Clin Nutr 2011; 94: 726-734.

5. Siega-Riz AM, Kinlaw A, Deming DM, Reidy KC. New findings from the Feeding Infants and Toddlers Study. Nestle Nutr Workshop Ser Pediatr Program 2008; 68: 83-100.

6. Palacios C, Joshipura K, Willett W. Nutrition and health: guidelines for dental practitioners. Oral Dis 2009; 15: 369381.

7. Ludwig DS, Peterson KE, Gortmaker SL. Relation between consumption of sugar-sweetened drinks and childhood obesity: a prospective, observational analysis. Lancet 2001; 357: 505-508.

8. Mattes RD. Dietary compensation by humans for supplemental energy provided as ethanol or carbohydrate in fluids. Physiol Behav 1996; 59: 179-187.

9. Popkin BM. Patterns of beverage use across the lifecycle. Physiol Behav 2010; 100: 4-9.

10. Barquera S, Campirano $F$, Bonvecchio $A$, Hernandez-Barrera L, Rivera JA, Popkin BM. Caloric beverage consumption patterns in Mexican children. Nutr J 2010; 9: 47.

11. Instituto Nacional de Salud Pública. Encuesta Nacional de Salud y Nutrición 2012. Resultados Nacionales. 1st edn. Instituto Nacional de Salud Pública: Cuernavaca, Morelos, Mexico, 2012.

12. Barlow SE. Expert committee recommendations regarding the prevention, assessment, and treatment of child and adolescent overweight and obesity: summary report. Pediatrics 2007; 120(Suppl. 4): S164-S192.

13. Rivera JA, Munoz-Hernandez O, Rosas-Peralta M, Aguilar-Salinas CA, Popkin BM, Willett WC. [Beverage consumption for a healthy life: recommendations for 
the Mexican population]. Rev Invest Clin 2008; 60: 157-180.

14. Secretaría de Salud. Bases Técnicas del Acuerdo Nacional para la Salud Alimentaria. Estrategia contra el Sobrepeso y la Obesidad. Secretaría de Salud: Distrito Federal, Mexico, 2010.

15. Instituto Nacional de Salud Pública. Documento técnico de recomendaciones para guías de alimentación en escuelas primarias públicas. Instituto Nacional de Salud Pública: Cuernavaca, Morelos, Mexico, 2010.

16. Park S, Pan L, Sherry B, Li R. The association of sugar-sweetened beverage intake during infancy with sugar-sweetened beverage intake at 6 years of age. Pediatrics 2014; 134(Suppl. 1): S56-S62.

17. Pan L, Li R, Park S, Galuska DA, Sherry B, Freedman DS. A longitudinal analysis of sugar-sweetened beverage intake in infancy and obesity at 6 years. Pediatrics 2014; 134(Suppl. 1): S29-S35.

18. Ettinger AS, Lamadrid-Figueroa $H$, Tellez-Rojo MM, et al. Effect of calcium supplementation on blood lead levels in pregnancy: a randomized placebo-controlled trial. Environ Health Perspect 2009; 117: 26-31.

19. Hu H, Tellez-Rojo MM, Bellinger D, et al. Fetal lead exposure at each stage of pregnancy as a predictor of infant mental development. Environ Health Perspect 2006; 114: 1730-1735.

20. Hernandez-Avila M, Romieu I, Parra S, HernandezAvila J, Madrigal H, Willett W. Validity and reproducibility of a food frequency questionnaire to assess dietary intake of women living in Mexico City. Salud Publica Mex 1998; 40: 133-140.

21. de Onis M, Onyango AW, Borghi E, Siyam A, Nishida C, Siekmann J. Development of a WHO growth reference for school-aged children and adolescents. Bull World Health Organ 2007; 85: 660-667.

22. Fernandez JR, Redden DT, Pietrobelli A, Allison DB. Waist circumference percentiles in nationally representative samples of African-American, European-American, and Mexican-American children and adolescents. I Pediatr 2004; 145: 439-444.

23. Hernandez B, Gortmaker SL, Laird NM, Colditz GA, Parra-Cabrera S, Peterson KE. [Validity and reproducibility of a questionnaire on physical activity and non-activity for school children in Mexico City]. Salud Publica Mex 2000; 42: 315-323.

24. Woodward-Lopez G, Kao J, Ritchie L. To what extent have sweetened beverages contributed to the obesity epidemic? Public Health Nutr 2011; 14: 499-509.

25. Martin RM, Patel R, Kramer MS, et al. Effects of promoting longer-term and exclusive breastfeeding on adiposity and insulin-like growth factor-I at age 11.5 years: a randomized trial. JAMA 2013; 309: 1005-1013.

26. Heitmann BL, Lissner L. Can adverse effects of dietary fat intake be overestimated as a consequence of dietary fat underreporting? Public Health Nutr 2005; 8: 1322-1327. 27. Malik VS, Pan A, Willett WC, Hu FB. Sugar-sweetened beverages and weight gain in children and adults: a systematic review and meta-analysis. Am J Clin Nutr 2013; 98: 1084-1102.

28. Kipnis V, Midthune D, Freedman L, et al. Bias in dietary-report instruments and its implications for nutritional epidemiology. Public Health Nutr 2002; 5(6A): 915923.

29. Andersen LF, Lande B, Trygg K, Hay G. Validation of a semi-quantitative food-frequency questionnaire used among 2-year-old Norwegian children. Public Health Nutr 2004 ; 7: 757-764.

30. Jensen BW, Nichols M, Allender S, et al. Inconsistent associations between sweet drink intake and 2-year change in BMI among Victorian children and adolescents. Pediatr Obes 2013; 8: 271-283.

\section{Supporting Information}

Additional Supporting Information may be found in the online version of this article at the publisher's web-site:

Figure S1. Relationship between cumulative SSB consumption during the pre-school period (total $\mathrm{mL}$ ) and concurrent SSB intake $\left(\mathrm{mL} \mathrm{d}^{-1}\right)$. Dots represent individuals $(N=227)$; solid line indicates fitted values; shaded area represents 95\% confidence band. 